\title{
Articulating Teachers' Expectations afore: Impact of Rubrics on Chinese EFL Learners' Self-Assessment and Speaking Ability
}

\author{
Yu Huang ${ }^{1}$, Min Gui ${ }^{1}$ \\ ${ }^{1}$ School of Foreign Languages and Literature, Wuhan University, China \\ Correspondence: Min Gui, School of Foreign Languages and Literature, Wuhan University, Wuhan Hubei 430072, \\ China
}

Received: February 28, 2015 Accepted: March 17, 2015 Online Published: April 3, 2015

doi:10.11114/jets.v3i3.753

URL: http://dx.doi.org/10.11114/jets.v3i3.753

\begin{abstract}
Under the constraint of classroom time, English as foreign language (EFL) learners usually do not have adequate opportunity to practice oral English in class nor receive individualized feedback from the instructor. After-class practice constitutes an essential component of foreign language learning. This study investigated the effect of utilizing rubrics on EFL learners' oral English using a 16-week experiment and a questionnaire. A total of 61 college students participated in the study, 41 in the rubric-mediated group and 20 in the control group. They were required to complete six tasks of three types: conversation, description, and discussion. Participants in the rubric-mediated group were provided with three rubrics describing respective task assessment criteria. They were also required to record their speaking, self-assess their performance with reference to the rubrics, revise their speaking if they noticed they did not meet the criteria, and finally complete a questionnaire. Students in the control group were assigned the same tasks but were not given the rubrics. Two oral tests were delivered at the initial and final stages of the study to measure the change in their speaking ability. Results revealed that rubrics had positive effects on discourse length, discourse organization, and linguistic flexibility but little impact on linguistic accuracy. Responses to the questionnaire indicated that students perceive rubrics as a facilitative tool of practice and self-assessment.
\end{abstract}

Keywords: rubrics, self-assessment, EFL speaking

\section{Introduction}

English as foreign language (EFL) learners in China have limited chances to practice oral English in class due, at least in part, to the large size of classes. To deal with this constraint, teachers often assigned after-class speaking tasks. However, lacking guidance in practice, most learners are not clearly aware of their own speaking weaknesses, nor do they know how to adopt varying strategies when facing different speaking tasks. Therefore, independent practice usually cannot produce the same effect as instructor guided in-class activities. To address the dilemma, the present study intends to investigate the extent to which rubrics may facilitate EFL students' oral English learning.

A rubric is a document that describes the expectations for an assignment in an analytical way. It is usually presented in two dimensions: a component of pre-established criteria and performance levels in which performance features of each level is described in contrast with those of other levels (Goodrich 1997; Andrade 2000; Stevens and Levi 2005) (see Appendix for an example).

Rubrics mainly serve two purposes, to grade student work and to guide students to complete an assignment (Arter and McTighe 2001; Stevens and Levi 2005). Regarding the first purpose, since performance features of each level have been described in detail beforehand, teachers only need to identify a corresponding level to match students' real performance when they rate students. Due to their efficiency, rubrics have been widely used to evaluate written papers, oral presentations, group projects and discussions (e.g. Campbell 2005; Dunbar et al. 2006).

Second, rubrics are used to facilitate learning by directing students' attention to specific areas, guiding them to make dependable judgments about the quality of their work, and assisting them to revise their work so as to target at a higher level. A number of researchers have investigated this instructional value of rubrics. Andrade and Du (2005) explored student perspectives on using rubrics to guide and assess students' learning of the course content. The students expressed seven benefits of rubrics. The most commonly cited one is that rubrics communicate the teacher's expectations of assignments and thereby provide guidelines for students' efforts. Other benefits include directing 
students to plan a process for a complicated task, assisting them to check and revise their performance, helping them better understand teachers' feedback, encouraging them to take efforts to earn a higher grade, and lowering their anxiety about an assignment.

Reynolds-Keefer (2010) examined how rubrics influenced 45 pre-service teachers' learning and the likelihood that they would use rubrics in the future as teachers. He designed two rubrics for two writing assignments, which presented teachers' requirements and expectations on five aspects of writing, i.e., development of argument, organization, mechanics and language, focus, and synthesis. The rubrics also described the features of these five aspects at different grade levels. The researcher also administered an open-ended questionnaire at the end of the study to investigate the participants' attitude toward the use of rubrics in the writing course. Results showed that the pre-service teachers had an overwhelming positive attitude towards the approach, and they also expressed their willingness to employ the tool of rubrics in their own future teaching.

Andrade and Boulay (2003) examined the impact of rubric-mediated self-assessment on 7th- and 8th-grade students' written essays. They implemented two written rubrics which articulated the criteria respectively for two assignments: a historical fiction essay and a response to literature essay. They found positive impact of rubrics on girls' but not boys' historical fiction essays. For the literature essay, no effect had been identified for either girls or boys.

About twenty more rubric studies have been reviewed by Reddy and Andrade (2010). The studies cover a wide variety of disciplines, including the liberal arts, information literacy, medicine, nursing, management, dentistry, food technology, teacher education and film technology. Some of the studies reported positive perceptions of rubrics from students and teachers. Some other studies documented that rubric use was associated with improved academic performance. This plethora of research has not only revealed the impact of rubrics on learning and achievement but also the popularity of using rubrics among teachers, for educational research is usually rooted in classroom instructions.

However, research on the use of rubrics in the educational context of mainland China is rare. Only one study has been identified. Thompson (2013) conducted a one-semester research project by creating and implementing a 150-item writing rubric to enhance feedback for first-year Chinese EFL learners' writing at the university level. Rubrics were used on a weekly basis. The writing tests showed that students had improved 4-7 percentage points from the beginning to the end of the class. Another study was conducted in Taiwan. Hung et al. (2013) examined the influence of using rubrics on Taiwanese undergraduates' oral presentations. The 18 participants were required to give three presentations on topics of their choice with a rubric for self-assessment. Results revealed that the use of a rubric enhanced students' understanding and awareness of the nature of presentations and led to improved performance.

The above review reveals a contrast between the dearth of research in mainland China and Taiwan and the popularity of investigation and applications of rubrics in western educational settings. As educational settings with a large number of EFL students, exploration of effective tools of self-assessment and practice will be of great significance. Two questions guide the present study:

1. Does rubric-mediated practice and self-assessment improve students' EFL speaking performance?

2. What are students' attitudes towards to the rubrics and perceptions of the impact of using rubrics for oral practice and self-assessment?

\section{Method}

\subsection{Participants}

Sixty-one first-year university students in a China participated in the study. They were aged from 18 to 20 and all of them had received English instruction for 7 to 12 years (including six years formal instruction in high school and English is an optional course in primary school). The experiment was conducted in two separate classes, with 41 students ( 23 females and 18 males) in the rubric-mediated group and 20 students ( 9 females and 11 males) in the control group. Their EFL level ranged from lower intermediate to upper intermediate, comparatively homogenous, since they sit a placement test when they entered the university.

\subsection{Instruments}

Four instruments were employed, namely, 1) two modified College English Test--Spoken English Tests (CET-SET), which were used for the pre- and post-tests to measure students' speaking ability in both the rubric-mediated and the control groups; 2) three rubrics for the rubric-mediated group; 3) six spoken tasks for both groups; and 4) an 8-item questionnaire, which was utilized to explore the rubric-mediated group' attitudes and perceptions of the impact of using rubrics.

\subsubsection{The Two Modified CET-SET Tests}

The two tests were adapted according to the national CET-SET. The test consisted of three parts: 1) self-introduction 
and short-questions, 2) oral description and discussion, and 3) follow-up questions. In part 1, all members of a group (normally three and in rare condition four members) were required to introduce themselves briefly and the interviewer asked each of them one or two questions. In part 2, each candidate was given a visual prompt, which was different from each other but sharing a common theme. For example, with the transportation theme, each candidate in the group was given a picture depicting one way of transportation, such as by taxi, by bus, or by bicycle. After one minute preparation, each candidate was allotted 1.5 minutes to describe the visual prompt as well as to make comments on it. The last part was a 4.5-minute group discussion on a topic which was related to the visual prompts. The interviewer ended the whole test with one follow-up question to each candidate.

\subsubsection{Three Rubrics}

The three rubrics used by the experimental group were designed by the authors (see Appendix). They were rubrics for the conversation, description, and group discussion tasks. The descriptors of the rubrics were guided by the Self-Assessment Form for Students' English Competence (College English Curriculum Requirements, 2007) and the rating scales of the CET-SET.

\subsubsection{Six Speaking Tasks}

Participants engaged in six speaking tasks: two conversation tasks, two oral description and two discussion tasks. They were assigned to both the rubric-mediated (experimental) and the control groups. The topics were chosen from the textbooks that they were using such as communication, entertainment, and advertisement.

\subsubsection{The Questionnaire}

The questionnaire was only administered to the experimental group. Its content covered two aspects: 1) students' attitude towards the rubric; 2) students' perceptions of the impact of using rubrics for oral practice and self-assessment. The questionnaire was composed of eight items, which were on a 5-point Likert-scale ranging from "strongly agree" to "strongly disagree".

\subsection{Procedure}

This study experienced three major phrases. As shown in Table 1, in the first two weeks of the semester, the researchers administered the pre-test to both groups. The participants were divided into groups of three and were tested by the two researchers. Their performances were measured according to the CET-SET rating scale (See Appendix E). An experienced examiner of the CET-SET trained the two researchers, elaborating the detailed gradation of the criterion. The whole process of oral tests was audio-recorded.

Table 1. The sequence of the experimental phases

\begin{tabular}{llll}
\hline Group & Weeks 1-2 & Weeks 3-14 & Weeks 15-16 \\
\hline Rubric-mediated & Pre-test & 6 speaking tasks with the use of rubrics & $\begin{array}{l}\text { Post-test \& } \\
\text { Questionnaire } \\
\text { Control }\end{array}$ \\
& Pre-test & 6 speaking tasks & Post-test \\
\hline
\end{tabular}

From the third week through the fourteenth, students in both groups were required to complete the six speaking tasks of three types, i.e., conversation, oral description, and group discussion. The first time each task type was assigned, students in the experimental group were given a corresponding rubric, and one of the researchers spent about five minutes explaining to students how to use the rubric to self-assess. Students were advised to follow four steps in their after-class practice, i.e., 1) practice the oral tasks and audio-record their performance; 2) assess their speaking with reference to the corresponding rubric by marking the areas that they needed to improve; 3) practice again with emphasis on the specific aspects they noticed from self-assessment; and 4) audio-record a final version that they were satisfied with and submit to the teacher via email. Students in the control group were assigned the same tasks. They were also required to practice, revise, and submit their recordings, but they had no rubric. After receiving the students recording the teacher randomly chose half of the assignments from both groups and provided oral feedback to the whole class in the following class.

\section{Results and Discussion}

This section will first present the results of the pre- and post tests of the participants' speaking performances. Second, participants' responses to the questionnaire will be displayed to explore participants' attitudes towards to the rubrics and perceptions of the impact of using rubrics for their oral practice and self-assessment.

Research question one: Does rubric-mediated practice and self-assessment improve students' EFL speaking performance?

Students' performance in the speaking tests was graded by two researchers. The reliability in pre-test and post-test of the 
two researchers were generally high, with Cronbach's Alpha level reaching 0.82 in the pre-test for the experiment group and 0.94 for the control group. The post-test reliability of the two groups was 0.86 and 0.93 , respectively.

Table 2. Pre-test statistics

\begin{tabular}{lllllll}
\hline \multirow{2}{*}{$\begin{array}{c}\text { Speaking subscales } \\
\text { (total score }=15)\end{array}$} & \multicolumn{2}{c}{$\begin{array}{c}\text { Experimental group } \\
(\mathrm{n}=41)\end{array}$} & $\begin{array}{c}\text { Control group } \\
(\mathrm{n}=20)\end{array}$ & & \\
\cline { 2 - 5 } & \multicolumn{7}{c}{ Mean } & $S D$ & Mean & $S D$ & $t$ & $p$ \\
1) Linguistic accuracy \& range & 3.34 & 0.52 & 3.15 & 0.52 & -1.360 & 0.182 \\
\hline 2) Discourse length \& organization & 3.22 & 0.63 & 3.18 & 0.59 & -0.270 & 0.789 \\
3) Flexibility \& appropriateness & 3.38 & 0.49 & 3.50 & 0.58 & 0.862 & 0.393 \\
Overall score & 9.94 & 1.50 & 9.83 & 1.41 & -0.290 & 0.773 \\
\hline
\end{tabular}

The CET-SET rating scale was employed to evaluate the participants' performances on the pre- and post-tests. The scale measures speaking by three subscales, including 1) linguistic accuracy and range, 2) discourse length and management, and 3) flexibility and appropriateness. Table 2 lists the mean as well as the standard deviation of the experimental and the controls groups. The results of the independent $\mathrm{t}$-test showed that the means of the two groups, neither in the three subscales nor the overall scores, were not significantly different $(p>0.05)$. Therefore, comparable speaking abilities between the two groups could be assumed. In addition, none of the participants received other English instructions besides the College English course. Considering these two factors, the post-test scores could be used to explore the differences between the experimental and the control groups.

Table 3. Post-test statistics

\begin{tabular}{|c|c|c|c|c|c|c|}
\hline \multirow{2}{*}{$\begin{array}{l}\text { Speaking subscales } \\
\text { (total score }=15 \text { ) }\end{array}$} & \multicolumn{2}{|c|}{$\begin{array}{c}\text { Experimental group } \\
(\mathrm{n}=41)\end{array}$} & \multicolumn{2}{|c|}{$\begin{array}{l}\text { Control group } \\
(\mathrm{n}=20)\end{array}$} & \multirow[b]{2}{*}{$t$} & \multirow[b]{2}{*}{$p$} \\
\hline & Mean & $S D$ & Mean & $S D$ & & \\
\hline 1) Linguistic accuracy \& range & 3.52 & 0.52 & 3.35 & 0.43 & -1.289 & 0.182 \\
\hline 2) Discourse length \& organization & 3.88 & 0.50 & 3.33 & 0.47 & -4.159 & 0.000 \\
\hline 3) Flexibility \& appropriateness & 4.17 & 0.43 & 3.75 & 0.47 & -3.486 & 0.001 \\
\hline Overall score & 11.57 & 1.30 & 10.43 & 1.17 & -0.290 & 0.001 \\
\hline
\end{tabular}

As can be seen in Table 3, among the three subscales of evaluating criteria, significant differences have been found in discourse length and management as well as in linguistic flexibility and appropriateness $(p<0.05)$. However, no significant difference has been identified in linguistic accuracy and range between two groups $(p>0.05)$. The overall scores between the two groups were also significant $(p<0.05)$.

Before the study, a common weakness among the students is that their utterances were short and brief, and their responses to questions were usually not expanded properly. After the length of oral tasks was specified in the rubrics, increasingly more students could describe an object with relevant details, narrate an event with specific information, support propositions with appropriate evidence, and provide a suitable lengthy response to a question. Similarly, after the requirements of discourse organization and the use of different expressions for a certain idea were listed in the rubrics, students have improved in these aspects, which were indicated in their higher scores than their previous performances and than those of the students who have not given the rubrics.

However, the results revealed that the rubrics produced little impact on participants' pronunciation, grammar accuracy, or the range of tense usage. Although some common pronunciation errors have been listed in the rubrics, guided by Gui's (2012) report, some students still cannot differentiate the contrasts between $/ 1 /-/ \mathrm{r} /$ or $/ \mathrm{th} /-/ \mathrm{s} /$, /r/ sound is mistakenly added to the endings of such words as "China" and "idea", or syllables are incorrectly added or deleted.

Research question two: What are students' attitudes towards to the rubrics and perceptions of the impact of using rubrics for oral practice and self-assessment?

An 8-item questionnaire was designed to investigate participants' attitudes towards to the rubrics and perceptions of the impact of using rubrics for oral practice and self-assessment. Items 1 through 4 intended to examine students' attitudes toward the rubrics, what they thought of the rubrics and whether they took the rubrics seriously. Items 5 to 7 were used to investigate how students perceived the influence of rubrics on their after-class practice and self-assessment. The last item intended to find if the students want to more rubrics in the future classes.

Responses to item 1 show that $71 \%$ (20\% strongly agree and $51 \%$ agree) of the participants thought that the rubrics were clearly written and easy to follow. This result implies that the rubrics still need to be optimized although most of the participants endorse the quality. The revision details should be further explored. 
Table 4. Attitudes toward and perceptions of the rubrics $(\mathrm{N}=41)$

\begin{tabular}{|c|c|c|c|c|c|}
\hline & Strongly agree & Agree & Neutral & Disagree & Strongly disagree \\
\hline \multirow[t]{2}{*}{1.} & The three speaking & s are clear & ded and er & ollow. & \\
\hline & $8(20 \%)$ & $21(51 \%)$ & $9(22 \%)$ & $3(7 \%)$ & $0(0 \%)$ \\
\hline \multirow[t]{2}{*}{2.} & I read the rubrics ca & before I e & my speal & rformance & \\
\hline & $8(20 \%)$ & $11(27 \%)$ & $17(41 \%)$ & $5(12 \%)$ & $0(0 \%)$ \\
\hline \multirow[t]{2}{*}{3.} & I revise and improv & nswer witl & nce to the & & \\
\hline & $9(22 \%)$ & $18(44 \%)$ & $12(29 \%)$ & $2(5 \%)$ & $0(0 \%)$ \\
\hline \multirow[t]{2}{*}{4.} & When I practice, I r & per the des & as in the $r$ & and revise 1 & nance accordingly. \\
\hline & $9(22 \%)$ & $21(51 \%)$ & $9(22 \%)$ & $2(5 \%)$ & $0(0 \%)$ \\
\hline \multirow[t]{2}{*}{5.} & The rubrics help me & stand teac & quiremen & & \\
\hline & $13(32 \%)$ & $22(54 \%)$ & $4(10 \%)$ & $2(5 \%)$ & $0(0 \%)$ \\
\hline \multirow[t]{2}{*}{6.} & With rubrics I spent & time on $\mathrm{sp}$ & nglish pra & & \\
\hline & $10(24 \%)$ & $19(46 \%)$ & $10(24 \%)$ & $2(5 \%)$ & $0(0 \%)$ \\
\hline \multirow[t]{2}{*}{7.} & Rubrics help me ide & ny strengt & weakness & glish Spea & \\
\hline & $15(37 \%)$ & $18(44 \%)$ & $5(12 \%)$ & $3(7 \%)$ & $0(0 \%)$ \\
\hline & $17(41 \%)$ & $19(46 \%)$ & $5(12 \%)$ & $0(0 \%)$ & $0(0 \%)$ \\
\hline
\end{tabular}

Answers to statement 2 indicate that fewer than half of the participants (20\% strongly agree and $27 \%$ agree) had read the rubrics carefully when they assessed their speaking performance recordings. This finding is in accordance with that of Andrade and Du's (2005) study, which found that "most of the students tend not to read a rubric in its entirety" (p.1). Perhaps the participants focused their attention on particular demands rather than the holistic requirement of a certain task. This assumption is supported by the responses to statement 3, which reveal that $66 \%$ of the students would revise and improve their speaking according to the descriptions of the rubrics. Replies to item 4 show that the $73 \%$ (22\% strongly agree and $51 \%$ agree) of participants also incorporated the rubric requirements into their practice. To sum up, the participants held an overall positive attitude toward the use of rubrics although most of them did not read through the rubrics carefully.

Responses to the subsequent three items, statements 5, 6, and 7, are used to explore how the participants perceived the impact of rubrics. To statement 5, "The rubrics help me understand teacher's requirements better", $86 \%$ participants (32\% strongly agree and $54 \%$ agree) responded positively. This function of communicating teachers' expectations ahead to students has been reported across almost all rubric studies (e.g., Andrade and Du 2005; Reynolds-Keefer 2010; Hung et al. 2013). Besides this bridging function between the teacher and the student, responses to item 6 also show that rubrics drove $70 \%$ (24\% strongly agree $46 \%$ agree) of the participants to spend more time practicing oral English after class. Item 7 of the questionnaire, regarding the impact of rubrics on self-assessment, $81 \%$ of the students (37\% strongly agree and $44 \%$ agree) responded that rubrics assisted them to identify their strengths and weaknesses in English Speaking. Overall most of the participants believed that rubrics produced a positive impact on understanding instructors' requirements and expectations, facilitating independent practice, and supporting self-assessment.

The last item concerns participants' willingness to use rubrics in the future. Results indicate that an overwhelming majority of the students $(87 \%)$ responded that they would like to use rubrics in the future oral English practice. This finding underscored Reynolds-Keefer's (2010) discovery that those who experienced the impact of rubrics are more likely to utilize them again.

In conclusion, the responses to the eight items of the questionnaire reveal that the participants in general hold a positive attitude toward the use of rubrics and a perception of positive impact on practice and self-assessment.

\section{Conclusion and Implications}

Noticing the gap between the frequent reports on facilitative functions of rubrics on learning in western countries and the paucity of such research in China, this study examined how speaking rubrics might influence Chinese undergraduates' EFL practice and ability. Their attitudes towards to the use of rubrics and perceptions of the impact of using rubrics have also been explored. Four major findings have been gleaned. First, the use of rubrics has exerted positive impact on students' oral discourse length and organization as well as vocabulary diversification.

Second, the use of rubrics produces little effect on pronunciation accuracy. This finding implies that teachers should design more pronunciation activities in class. Pronunciation is one of the most challenging skills that can hardly acquire by self-learning. Teachers should clearly differentiate skills which necessitate face-to-face instructions from those that can be learned by students themselves and assign tasks appropriately.

Third, students in general held a positive and cooperative attitude toward the use of rubrics in EFL learning. Most of the 
students employed rubrics as a standard, with which they compared their speaking recordings, guide their practice, and revise their performance accordingly, which contrasted with teachers' presumption before the study that the students might not take the rubrics seriously. Their embracing attitude toward the use of rubrics as well as their willingness to be guided by further rubrics could be viewed as evidence that more teachers should be encouraged to try out this approach.

Last, rubrics produce positive impact on students' practice and self-assessment. The rubrics, especially the specific descriptions of the different levels in evaluation make students feel that a higher grade is within reach once more effort is invested. This has greatly motivated the students to practice more frequently. Furthermore, rubrics raise students' awareness of their speaking strengths and weaknesses, and therefore direct their attention and efforts to specifics areas of their speaking.

After reporting these four major findings, discussion about a less favorable finding might be a good segue to the final point, future research. This study, as well as Andrade and Du's (2005), found that only half of the students read the rubrics in its entirety. Exploration of the reasons behind this phenomenon might shed light on the design of rubrics. Reddy and Andrade (2010) also expressed their concern about the quality of rubrics in research. They proposed that "Future studies should report how the validity of a rubric was established, and the scoring reliability, including rater training and its contribution towards achieving inter-rater reliability, and perhaps even the correlation between rubric-referenced scores and other measures of performance" (p.446). It is hoped that discussion about the approaches to design highly valid and reliable rubrics as well as further investigation about the impact of rubrics on learning might inspire more teachers' interest in the use of rubrics.

\section{Acknowledgments}

This research was partially supported by the Academy of Humanities and Social Sciences, Wuhan University, China under the grant of 2012GSP093-102274118.

\section{References}

Andrade, H. (2000).Using rubrics to promote thinking and learning. Educational Leadership, 57(5), 13-18.

Andrade, H., \& Du, Y. (2005).Student perspectives on rubric-referenced assessment.Practical Assessment. Research \& Evaluation, 10(4). http://pareonline.net/getvn.asp?v=10\&n=3.

Andrade, H., \& Boulay, B. (2003). Role of rubric-referenced self-assessment in learning to write. The Journal of Educational Research, 97 (1), 21-34. http://dx.doi.org/10.1080/00220670309596625

Andrade, H., Du, Y., \& Wang, X. (2008). Putting rubrics to the test: The effect of a model, criteria generation, and rubric-referenced self-assessment on elementary school students' writing. Educational Measurement: Issues and Practices, 27 (2), 3-13. http://dx.doi.org/10.1111/j.1745-3992.2008.00118.x

Arter, J., \& McTighe, J. (2001). Scoring rubrics in the classroom: using performance criteria for assessing and improving student performance. Thousand Oaks, CA: Corwin Press.

Campbell, A. (2005). Application of ICT and rubrics to the assessment process where professional judgment is involved: the features of an e-marking tool. Assessment \& Evaluation in Higher Education, 30 (5), 529-537. http://dx.doi.org/10.1080/02602930500187055

Dunbar, N. E., Brooks, C. F., \& Kubicka-Miller, T. (2006). Oral communication skills in higher education: Using a performance-based evaluation rubric to assess communication skills. Innovative Higher Education, 31(2), 115-128. http://dx.doi.org/10.1007/s10755-006-9012-x

Gui, M. (2012). Exploring differences between Chinese and American EFL teachers' evaluations of speech performance. Language Assessment Quarterly, 9(2), 186-203. http://dx.doi.org/10.1080/15434303.2011.614030

Goodrich, H. (1997). Understanding rubrics. Educational Leadership, 54(4), 14-17.

Hung, H., Chiu Y. J., \&Yeh, H. (2013). Multimodal assessment of and for learning: A theory-driven design rubric. British Journal of Educational Technology, 22 (3), 400-409. http://dx.doi.org/10.1111/j.1467-8535.2012.01337.x

Reynolds-Keefer, L. (2010). Rubric-referenced assessment in teacher preparation: An opportunity to learn by using. Practical Assessment. Research \& Evaluation, 15 (8). http://pareonline.net/getvn.asp?v=15\&n=8.

Reddy, Y. M., \& Andrade, H. (2010). A review of rubric in higher education. Assessment \& Evaluation in Higher Education, 35(4), 435-448. http://dx.doi.org/10.1080/02602930902862859

Stevens, J., \& Levi, A. (2005). Introduction to Rubrics. Sterling, Virginia: Stylus Publishing.

Thompson, J. (2013). A writing rubric for Chinese university EFL students. Chinese Journal of Applied Linguistics, 36(2), 183-194. http://dx.doi.org/10.1515/cjal-2013-0012 


\section{Appendix}

Picture description assignment rubric (20 points)

\begin{tabular}{|c|c|c|c|c|}
\hline Domain & 5 points & 4 points & 3 points & 2 points $^{*}$ \\
\hline $\begin{array}{l}\text { Pronunciation } \\
\text { and intelligibility }\end{array}$ & $\begin{array}{l}\text { - shows clear } \\
\text { pronunciation } \\
\text { - is effortless to } \\
\text { understand } \\
\text { - uses a full range of } \\
\text { pronunciation features, } \\
\text { such as liaison, } \\
\text { contraction, and } \\
\text { reduction }\end{array}$ & $\begin{array}{l}\text { - shows no serious } \\
\text { pronunciation } \\
\text { problems } \\
\text { a is easy to understand } \\
\text { - shows some } \\
\text { pronunciation } \\
\text { features, such as } \\
\text { liaison, contraction, } \\
\text { and reduction }\end{array}$ & $\begin{array}{l}\text { makes pronunciation } \\
\text { mistakes occasionally } \\
\text { - speaks in sense groups } \\
\text { most of the time } \\
\text { - has limited ability to } \\
\text { speak with liaison, } \\
\text { contraction, or } \\
\text { reduction }\end{array}$ & $\begin{array}{l}\text { mispronounces words } \\
\text { often } \\
\text { - is hard to understand } \\
\text { - speaks with no clear } \\
\text { sentence stress, or } \\
\text { sense groups }\end{array}$ \\
\hline $\begin{array}{l}\text { Grammar and } \\
\text { vocabulary }\end{array}$ & $\begin{array}{l}\text { - produces accurate } \\
\text { sentence structures } \\
\text { consistently } \\
\text { - uses words with high } \\
\text { flexibility and precision } \\
\text { - uses descriptive words } \\
\text { appropriately } \\
\text { - uses connectives } \\
\text { naturally }\end{array}$ & $\begin{array}{l}\text { - produces accurate } \\
\text { sentence structures } \\
\text { most of the time } \\
\text { - uses words with } \\
\text { some flexibility } \\
\text { - shows awareness of } \\
\text { using connectives }\end{array}$ & $\begin{array}{l}\text { makes some mistakes } \\
\text { in sentence structures } \\
\text { uses words with } \\
\text { limited accuracy and } \\
\text { flexibility }\end{array}$ & $\begin{array}{l}\text { - makes grammar errors } \\
\text { often which } \\
\text { sometimes lead to } \\
\text { misunderstanding } \\
\text { - uses simple words } \\
\text { repetitively } \\
\text { - attempts to use words } \\
\text { of similar meaning but } \\
\text { fail }\end{array}$ \\
\hline $\begin{array}{l}\text { Details of } \\
\text { description, } \\
\text { discourse length, } \\
\text { and organization }\end{array}$ & $\begin{array}{l}\text { - describes pictures } \\
\text { thoroughly and } \\
\text { correctly including } \\
\text { almost every detail } \\
\text { - follows a clear order } \\
\text { (e.g., from most salient } \\
\text { features to less } \\
\text { important ones, from } \\
\text { center to the } \\
\text { surrounding) } \\
\text { makes full use of } 1.5 \\
\text { minutes allotted for the } \\
\text { description task, and } \\
\text { produces at least } 150 \\
\text { words** in this time } \\
\text { slot }\end{array}$ & $\begin{array}{l}\text { - describes most } \\
\text { features of the } \\
\text { picture clearly } \\
\text { - organizes most of the } \\
\text { descriptions in an } \\
\text { appropriate way } \\
\text { - produces about } 130 \\
\text { words in } 1.5 \text { minutes }\end{array}$ & $\begin{array}{l}\text { - describes some of the } \\
\text { features in the picture. } \\
\text { - shows some } \\
\text { misunderstanding of } \\
\text { the information } \\
\text { arranges some of the } \\
\text { descriptions poorly } \\
\text { - produces about } 100 \\
\text { words in } 1.5 \text { minutes }\end{array}$ & $\begin{array}{l}\text { - describes few features } \\
\text { in the picture } \\
\text { - gives incorrect } \\
\text { information } \\
\text { - shows no order of the } \\
\text { description } \\
\text { - produces fewer than } \\
80 \text { words in total }\end{array}$ \\
\hline $\begin{array}{l}\text { Fluency and } \\
\text { coherence }\end{array}$ & $\begin{array}{l}\text { - speaks fluently with } \\
\text { little repetition or } \\
\text { hesitation } \\
\text { - develops ideas in a } \\
\text { natural and logical way }\end{array}$ & $\begin{array}{l}\text { - speak fluently but } \\
\text { with some pauses, } \\
\text { hesitation, and } \\
\text { self-corrections } \\
\text { - develops most of } \\
\text { messages logically }\end{array}$ & $\begin{array}{l}\text { - speaks with frequent } \\
\text { pauses and hesitations } \\
\text { due to searching words } \\
\text { or ideas } \\
\text { - shows some ability to } \\
\text { let sentence idea } \\
\text { develop naturally }\end{array}$ & $\begin{array}{l}\text { - speak with long } \\
\text { pauses } \\
\text { - has limited ability to } \\
\text { link sentences }\end{array}$ \\
\hline
\end{tabular}

Notes: * The grade level of 1 point has not been presented since almost no student in this sample was at 1 point level.

** The requirements of the speech rate were based on another study by the researchers. They found the average speech rate is about 80 words per minute for a similar group of students.

This work is licensed under a Creative Commons Attribution 3.0 License. 